\title{
Trophic structure of arthropods in Starling nests matter to blood parasites and thereby to nestling development
}

\author{
Peter H. J. Wolfs • Izabela K. Lesna • \\ Maurice W. Sabelis · Jan Komdeur
}

Received: 23 September 2011 / Revised: 16 January 2012/ Accepted: 30 January 2012/Published online: 19 February 2012

(C) The Author(s) 2012. This article is published with open access at Springerlink.com

\begin{abstract}
Nestling development and long-term survival in many bird species depend on factors such as parental feeding, time of breeding and environmental conditions. However, little research has been carried out on the effect of ectoparasites on nestling development, and no research on the impact of the trophic structure of arthropods inhabiting the nest (combined effects of ectoparasitic mites and predatory mites feeding on ectoparasites). We assess nestling development of European Starlings (Sturnus vulgaris) in relation to the number of parasitic mites Dermanyssus gallinae (DG, a blood-sucking mite) and their predators, i.e. Androlaelaps casalis (AC), both dominant species of nidicolous arthropods in Starling nests. DG densities were not associated with nestling body mass or tarsus length during development (10 and 17 days of age), which contradicts our expectation that parasitic mites negatively influence growth. Furthermore, an increase in AC densities was associated with a significant decrease in body mass (not tarsus length) later during nestling development (at day 17-a proxy for nestling age-but not at day 10). The latter seems counterintuitive, but not when the
\end{abstract}

Communicated by F. Bairlein.

P. H. J. Wolfs · I. K. Lesna · J. Komdeur $(\bowtie)$

Behavioural Ecology and Self-organization, Centre for Ecological and Evolutionary Studies, Centre for Life Sciences, University of Groningen, Building 5172.05.52, Nijenborgh 7, 9747 AG Groningen, The Netherlands

e-mail: j.komdeur@rug.nl

P. H. J. Wolfs

e-mail: peter.wolfs@gmail.com

I. K. Lesna · M. W. Sabelis

Section Population Biology, Institute of Biodiversity and Ecosystem Dynamics, University of Amsterdam, Science Park 904, 1098 XH Amsterdam, The Netherlands inherent density-dependent delays in Lotka-Volterra predator-prey interactions are taken into account: a high density of predatory mites (AC) always arises after an increase of prey mites (DG). Thus, the high density of predatory mites indicates a preceding peak density of parasitic mites. Clearly, this explanation requires insight in the trophic structure of mites inhabiting Starling nests and bird nests in general. We conclude that multitrophic interactions (between predator, parasite and host) in nests should not be ignored when assessing nestling development.

Keywords Cosmopolitan nest mite $\cdot$ Nidicole $\cdot$ Poultry red mite $\cdot$ Starling $\cdot$ Trophic structure $\cdot$ Predator-prey interaction $\cdot$ Parasite-host interaction

\section{Zusammenfassung}

Die trophische Struktur der Arthropoden in Starennestern ist für Blutparasiten und damit für die Nestlingsentwicklung von Bedeutung

Die Nestlingsentwicklung und das langfristige Überleben hängen bei vielen Vogelarten von Faktoren wie Fütterung durch die Elternvögel, Zeitpunkt des Brütens und Umweltbedingungen ab. Bislang sind jedoch nur wenige Untersuchungen zum Effekt von Ektoparasiten auf die Nestlingsentwicklung und gar keine zum Einfluss der trophischen Struktur der Arthropoden, die das Nest bewohnen (Kombinationseffekte von ektoparasitischen Milben und räuberischen Milben, die sich von den Ektoparasiten ernähren) durchgeführt worden. Wir stellen die Nestlingsentwicklung bei Staren (Sturnus vulgaris) fest in Bezug auf die Anzahl von parasitischen Milben Dermanyssus gallinae (DG, einer blutsaugenden Milbe) und ihren Feinden, d. h. Androlaelaps casalis (AC), zwei Arten von als Nestgast 
lebenden Arthropoden, die in Starennestern dominant sind. Die DG-Dichten standen nicht mit der Körpermasse oder Tarsuslänge der Nestlinge während der Entwicklung (10. und 17.Lebenstag) in Zusammenhang, was unserer Erwartung widerspricht, dass parasitische Milben das Wachstum negativ beeinflussen. Des Weiteren stand ein Anstieg der AC-Dichte mit einer signifikanten Abnahme der Körpermasse (nicht jedoch der Tarsuslänge) später in der Nestlingsentwicklung (am 17., aber nicht am 10. Lebenstag) in Zusammenhang. Letzteres scheint der Intuition zu widersprechen, jedoch nicht, wenn die inhärenten dichteabhängigen Verzögerungen in Lotka-Volterra RäuberBeute-Interaktionen in Betracht gezogen werden: Eine hohe Dichte räuberischer Milben (AC) tritt immer nach einem Anstieg der Dichte der Beutemilben (DG) auf. Daher zeigt die hohe Dichte räuberischer Milben eine vorangehende Höchstdichte parasitischer Milben an. Diese Erklärung setzt eine Kenntnis der trophischen Struktur von Milben, die Starennester und Vogelnester im Allgemeinen bewohnen, voraus. Wir schlussfolgern, dass multitrophische Interaktionen (zwischen Räuber, Parasit und Wirt) in Nestern nicht ignoriert werden sollten, wenn die Nestlingsentwicklung bewertet wird.

\section{Introduction}

It is well known that fledging success in birds is greatly determined by nestling mass at the time of fledging (e.g. Lemel 1989; Krist 2009; Wilkin et al. 2009). Ample research has been carried out on nestling development and first year survival in many bird species, focusing on effects of parental feeding (Ardia 2007; Krist 2009), brood size and composition (Ardia 2007), time of breeding (Verboven and Visser 1998) and environmental conditions (Sillanpää et al. 2009). Although several studies have been carried out on the effect of ectoparasites on nestling development and breeding success (Johnson and Albrecht 1993; Bauchau 1997; Thomas and Shutler 2001; Eggert and Jodice 2008), to the best of our knowledge, no research has been carried out on the impact of the microhabitat of the nest and the trophic structure of arthropods inhabiting the nest (combined effects of ectoparasitic mites and predatory mites that feed on the ectoparasites). The only known studies on the effects of ectoparasites on breeding success in holebreeding birds showed a negative effect on breeding success and nestling condition (e.g. Clark and Mason 1988; Weddle 2000; Badyaev et al. 2006; Tomas et al. 2007; Carleton 2008) and fecundity of adults (Clayton and Tompkins 1995).

One of the more serious ectoparasites is Dermanyssus gallinae (DG; or poultry red mite), a blood-sucking mite that lives in nests of birds and small mammals. The parasitic mite $D$. gallinae appears to be generally present in bird nests and may have important implications for productivity in birds, especially considering that it is a worldwide pest in the poultry industry, resulting in increased food consumption, anaemia, lower egg quality and production of chickens (Kirkwood 1967; Axtell and Arends 1990; Chauve 1998). It also occurs in nests of holebreeding birds. Hole-breeding birds are special in that they nest in cavities, either natural (e.g. tree holes) or man-made (nest-boxes). Because the number of cavities suitable for nesting are limiting, they have a high probability of being used several times within and over years. This nest-site re-use provides adequate time for community build-up of arthropods with different degrees of specialisation in the nest as a microhabitat, such that not only detritivores and parasites may be present in the nest but also their predators. While there is a vast literature on faunal inventories of nidicolous arthropods and on (putative) ectoparasites affecting bird breeding success, no research has been carried out on the impact of the trophic structure of arthropods inhabiting the nest. For example, the cosmopolitan nest mite Androlaelaps casalis (AC) has been assumed to be an opportunistic feeder, preying on other mites and mite eggs, and to resort to ectoparasitism feeding on blood, lymph, faeces and egg yolk in bird nests (e.g. Men 1959; Barker 1968; Radovsky 1985, 1994; Pacejka et al. 1998; Pung et al. 2000). However, an experimental study showed that this mite cannot directly obtain blood from a living bird, but only indirectly by feeding on free blood droplets or on a true ectoparasite of birds, like DG (Lesna et al. 2009). Whereas negative effects of other parasitic mites, like DG, have been demonstrated with respect to host reproductive success, the adverse effects of AC on reproductive output and development in birds remain unclear (Pacejka et al. 1998; Pung et al. 2000). As such, AC is able to influence and control ectoparasite populations in the nests of holebreeding birds, in our case, the European Starling (Sturnus vulgaris) and in (at least some types of) poultry houses (Lesna et al. 2009; Sabelis et al. 2010) Thus, to quantify the ectoparasite load imposed on birds, it is necessary to identify and count genuine ectoparasites over the entire period of nestling development. Usually, only a snapshot of ectoparasite load can be obtained (e.g. just before fledging) (Fauth et al. 1991; Szabó et al. 2002; Nilsson 2003), because frequent disturbance may hinder breeding success or because arthropod sampling may be destructive to the nest. In that case, it may be informative to assess not only the parasite densities but also the densities of their predators, because information on parasites and their predators may help to reconstruct the dynamics of ectoparasites and thereby parasite exposure of the nestling during its entire development (Lesna et al. 2012). 
Several studies have been conducted considering ectoparasitic infections by the northern fowl mite Ornithonyssus sylviarum in European Starling nests in the USA (Clark and Mason 1985, 1988; Fauth et al. 1991), and infections by DG in Europe (Gwinner et al. 2000; Brouwer and Komdeur 2004; Gwinner and Berger 2005). These yielded varying and contrasting outcomes of parasitism on nestling development and condition. Although the above-mentioned studies, and many other studies on nidicolous mites in bird nests, focus on the parasitic mite population, none have taken the trophic role of other nidicolous mites into account (Proctor and Owens 2000). Here, we investigate, to our knowledge for the first time, the development of young European Starlings in relation to the number of parasitic mites Dermanyssus gallinae (blood-sucking mite) and their predators, i.e. the cosmopolitan nest mite Androlaelaps casalis. We use the European Starling as a model species, because their nests contain DG and AC, both dominant species of nidicolous mites in these nests (Lesna et al. 2009). We build on our previous discovery that A. casalis is a true predator of $D$. gallinae and not a parasite of birds (Lesna et al. 2009). To assess the association between nestling development and mite densities, we measured the condition of the same nestlings at two different times after hatching (days 10 and 17) and related this to parasitic and predatory mite densities in the nest measured immediately after fledging (day 23), in order not to disturb the trophic structure of mites inhabiting the nest when nestlings were still present.

\section{Methods}

We collected data from 97 Starling nestlings hatched from 22 broods in nest-boxes located at Vosbergen Estate $\left(53^{\circ} 08^{\prime} \mathrm{N}, 06^{\circ} 35^{\prime} \mathrm{E}\right)$ in The Netherlands in 2007. Nest material present in the nest-boxes from the 2006 breeding season was not removed, to allow community build-up of arthropods in the nest (see also Lesna et al. 2009).

Occupied nest-boxes were checked daily during the nest building phase from mid-March between 1100 and 1230 hours to obtain the laying date of the first egg and to determine clutch size and to predict hatching date. Each newly laid egg within a clutch was numbered with indelible ink and the laying date was recorded. From day 9 of clutch completion ( 2 days before the predicted hatching date), we checked the nest-box daily to determine the actual hatching date of the first nestling and of each numbered egg. The hatching of the first young in a clutch was taken as the hatching date of the complete brood (day 0). Observations on later-hatched nestlings were related to hatching of the first young. Hatchlings were uniquely marked within $24 \mathrm{~h}$ of hatching, by clipping the very tip of 1 or 2 toenails in a specific combination. On days 10 and 17 , all nestlings were counted and individuals present and missing were identified and recorded. Each identified nestling still alive was investigated to assess age (calculated as whole days from hatching), body mass (measured to the nearest $0.1 \mathrm{~g}$ using 100-g Pesola balance) and tarsus (measured to the nearest $0.1 \mathrm{~mm}$ using vernier callipers), always by the same observer (P.H.J.W.). These two sampling dates were selected because, at day 10 , nestling mass approached a maximum, and then declined definitely after day 17 , until after fledging at approximately day 20 (Lemel 1989; J. Komdeur, unpublished data). At day 17 of each nestling, a small blood sample (ca. 5-25 ml) was taken from the tarsal vein for molecular sex determination (Griffiths et al. 1998). Because female condition may influence nestling development (e.g. Bernardo 1996; Merilä et al. 2001), females (17 of 22) were taken from the nest at night by the time their nestlings were 2-5 days old, and measured for body mass and tarsus length as estimates for female condition. On day 23 (1-3 days after the completion of fledging of the entire brood), nests were collected and placed on Berlese funnels for $72 \mathrm{~h}$. Mite species collected in the alcohol-filled vials under the funnels were identified (Lesna et al. 2009). For an inventory of mite species found in the Starling nests, we refer to Lesna et al. (2009). Our focus in this article will be on densities of DG and AC and nestling development.

\section{Data analyses}

For each nest, densities of DG and AC were estimated and scaled into six categories related to the amount of individual mites present (numbers: $1 ; 5 ; 50 ; 500 ; 5,000 ; 50,000)$. These were subsequently $\log _{10}$-transformed. An arbitrary categorical value of 1 was recorded in case no mites (DG or AC) were found. Body mass and tarsus length were normally distributed at days 10 and 17 . For nestlings, body mass was positively correlated with tarsus length on day 10 as well as day 17 (Pearsons correlation: $r_{\mathrm{p}}=0.65, n=97, P<0.001$, and $r_{\mathrm{p}}=0.39, n=91, P<0.001$, respectively). Therefore, in the analyses of body mass, we included tarsus length as a factor, and, vice versa in the analyses of tarsus length, we included body mass as a factor (Green 2001). Although nestling body mass was positively correlated with nestling tarsus length, we decided to analyse the effects of DG and AG densities on body mass and tarsus length separately, since an earlier study demonstrated effects of blood sucking mites on growth of nestling tarsus length, as well as variance in nestling mass (Merino and Potti 1995). To compare nestlings within broods, we calculated for each nestling its relative body mass (nestling body mass minus mean brood body mass) and its relative tarsus length (nestling tarsus length minus mean brood tarsus length). We realize that our 
data represent a repeated measures structure and should be analysed as such to test for an effect of DG density and AC density on the change in body mass and tarsus length across the two age classes. However, the fact that sex and age have different effects at different ages (see "Results") complicated a repeated measures analysis. As such, we analysed both dependent variables using a hierarchical mixed-model using MLwiN 2.10 (Rabash et al. 2008), to account for the non-independence and hierarchical structure of nestlings within nests. These models included a random component with nest identity at level 2 and nestling identity at level 1 . Nestling mass and tarsus length at days 10 and 17 were tested in separate models for correlations with nestling sex, hatching date, brood size (at days 10 and 17, respectively), adult female body mass and tarsus length (Pearsons correlation: $\left.r_{\mathrm{p}}=-0.10, n=17, P=0.70\right)$, exact nestling age, as well as DG and AC densities. Using backward elimination, the best-fitting statistical model was obtained. We eliminated variables with the highest $P$ value one by one, until all remaining variables had a $P$ value smaller than 0.05 . We reported non-significant parameters and retested them separately after elimination in the final model. In case the inclusion of a variable had a nearly significant $P$ value, the change in model deviance (which approximates a normal $\chi^{2}$ distribution) was calculated and tested for significance in model fit. We chose not to use the overall change in body mass or tarsus length between day 10 and day 17 as a dependent variable, because it stands to reason to relate this to a change in mite density over the same period, a quantity we cannot calculate since mite density could not be assessed until after fledging.

\section{Results}

At day 10, nestling body mass was not correlated with either DG or AC densities (Table 1; Fig. 1). The best model explaining nestling body mass included nestling age and relative tarsus length at day 10 (Table 1). At day 17, nestling body mass was not correlated with DG densities, but was negatively correlated with AC densities (Table 1; Fig. 1). Although female nestlings had significantly lower body mass than male nestlings, the correlation with AC densities was not significantly different between the sexes (interaction $\mathrm{AC} \times$ sex). We retested the rejected parameters in the best model for explaining nestling mass at days 10 and 17 , but none of these were significant (Table 1).

At day 10, nestling tarsus length was not correlated with either DG or AC densities (Table 2). The best model explaining nestling tarsus length included only relative nestling mass (Table 2). At day 17, the best explaining model not only included relative nestling mass but also incorporated hatch date (Table 2).

\section{Discussion}

We found no significant correlations of the ultimate (day 23) density of the parasitic mite DG with either the body mass or the tarsus length of Starling nestlings during their development (days 10 and 17). Although this is in line with other Starling studies (Fauth et al. 1991; Gwinner and Berger 2005), it contradicts our expectation that parasitic mites negatively influence growth (e.g. Axtell and Arends 1990; Weddle 2000). Furthermore, we found that an increase in the ultimate (day 23) density of the predatory mite AC was associated with a decrease in body mass later during nestling development (day 17, but not at day 10), but not with tarsus length. This also does not meet our expectation, since we previously found that the predatory mite AC negatively influences DG densities (Lesna et al. 2009), and we would expect an increase of nestling condition with an increase of AC densities.

Our study demonstrates that nestling condition in Starlings was unrelated to natural variation in the abundance of parasitic mites (Dermanyssus gallinae), but negatively related to the abundance of predatory mites (Androlealaps casalis) at one of two different nestling ages. We can only come up with one interpretation of these results, which is consistent with the fact that DG is a parasite and AC is a predator. The common use of parasitic loads in nests measured after nest-leaving may be biased because of predation on the parasites, resulting in lack of relationship between nestling body mass and ecto-parasite infestation rates. Since both DG and AC go through ca. 3 generations during nestling growth (I.K. Lesna, unpublished data) and their densities depend on each other, a higher density of AC is likely to arise from an initially higher density of DG, thus representing a larger prey resource. In fact, every $\mathrm{AC}$ individual present after the nestlings fledged (day 23) corresponds to a certain number of DG killed during nestling development. From this point of view, a high density of AC reflects high parasitic pressure during nestling development, which in turn may lead to a decrease in body mass.

For the observation that we found no negative correlation between natural DG densities and nestling condition, there are three alternative interpretations of our results, which are not necessarily mutually exclusive. First, a negative correlation between DG densities and nestling body mass may be obscured by parental quality (Bauchau 1997) or by increased begging behaviour of parasitised nestlings, which leads to increased parental provisioning, as was found in the Great Tit (Parus major; Christe et al. 1996). Bauchau (1997) found that mite densities did not directly influence body mass in Pied Flycatchers (Ficedula hypoleuca) and suggested that parental quality may have been influencing nestling growth. Second, mite densities were estimated at day 23 , and finding no correlation between day 10 nestling 
Table 1 MLwiN 2.10 models of European Starling (Sturnus vulgaris) nestling body mass at day 10 (97 nestlings, 22 broods) and nestling body mass at day 17 (88 nestlings, 22 broods)

Social female biometrics were determined at day 3-5 and mite densities at day 23

Significant values $(P<0.05)$ are shown in bold

${ }^{a}$ In both day 10 and day 17 analyses, sample sizes for models where social female biometrics were included, were reduced (66 nestlings, 17 females out of 22 nest-boxes). Original sample sizes where restored after reinsertion of the variable other than social female biometrics in the model

\begin{tabular}{|c|c|c|c|}
\hline & Coefficient (SE) & Wald $\left(\chi^{2}\right)$ & $P$ \\
\hline \multicolumn{4}{|l|}{ Day 10} \\
\hline Nestling sex & $-0.024(0.118)$ & 0.041 & 0.84 \\
\hline Hatch date & $0.067(0.075)$ & 0.810 & 0.37 \\
\hline Brood size & $0.106(0.175)$ & 0.364 & 0.55 \\
\hline Nestling age & $0.426(0.125)$ & 11.589 & $<\mathbf{0 . 0 0 1}$ \\
\hline Relative nestling tarsus & $0.483(0.072)$ & 45.450 & $<\mathbf{0 . 0 0 1}$ \\
\hline Social female mass ${ }^{\mathrm{a}}$ & $0.005(0.022)$ & 0.053 & 0.82 \\
\hline Social female tarsus ${ }^{\mathrm{a}}$ & $0.086(0.131)$ & 0.435 & 0.51 \\
\hline D. gallinae density (day 23) & $0.110(0.081)$ & 1.843 & 0.17 \\
\hline A. casalis density (day 23) & $-0.034(0.066)$ & 0.259 & 0.61 \\
\hline \multicolumn{4}{|l|}{ Day 17} \\
\hline Nestling sex & $0.552(0.164)$ & 11.355 & $<\mathbf{0 . 0 0 1}$ \\
\hline Hatch date & $-0.130(0.079)$ & 2.710 & 0.10 \\
\hline Brood size & $0.179(0.166)$ & 1.162 & 0.28 \\
\hline Nestling age & $0.199(0.181)$ & 1.212 & 0.27 \\
\hline Relative nestling tarsus & $0.307(0.095)$ & 10.397 & $<\mathbf{0 . 0 0 1}$ \\
\hline Social female mass ${ }^{\mathrm{a}}$ & $0.009(0.026)$ & 0.131 & 0.29 \\
\hline Social female tarsus ${ }^{\mathrm{a}}$ & $0.203(0.156)$ & 1.708 & 0.19 \\
\hline D. gallinae density (day 23 ) & $0.085(0.096)$ & 0.790 & 0.37 \\
\hline A. casalis density (day 23 ) & $-0.135(0.067)$ & 4.090 & 0.043 \\
\hline A. casalis density $\times$ nestling sex & $-0.070(0.093)$ & 0.570 & 0.45 \\
\hline
\end{tabular}

Fig. 1 The association between either Dermanyssus gallinae or Androlaelaps casalis densities measured at day $23\left(\log _{10^{-}}\right.$ transformed) on nestling body mass of the European Starling (Sturnus vulgaris) (standardized residual mass) measured at day 10 (91 nestlings, 22 nests) and day 17 (88, 22 nests; correlation Androlaelaps casalis densities versus nestling body mass day 17: $\chi^{2}=3.907$; fitted regression model (where $x=\mathrm{AC}$ densities) for nestling body mass has the formula $y=$ $-0.180 x+0.512, r^{2}=0.230$, $\chi^{2}=4.090, n=88, P=0.04$. Circles denote means and bars represent standard errors per nest

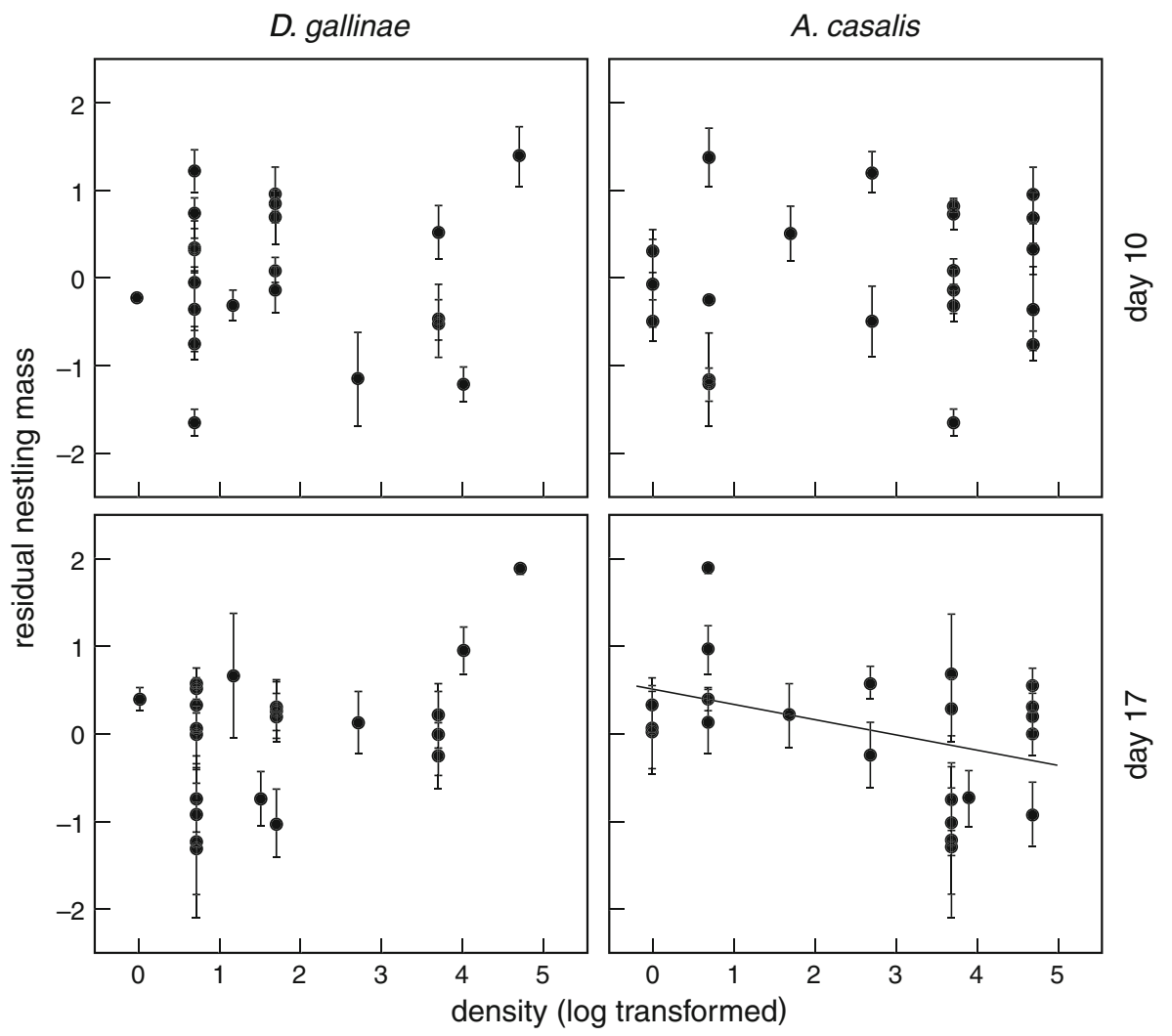


Table 2 MLwiN 2.10 models of Starling nestling tarsus length at day 10 (97 nestlings,

21 broods) and at day 17

(88 nestlings, 22 broods)

Social female biometrics were determined at day 3-5 and mite densities at day 23

Significant values $(P<0.05)$ are shown in bold

${ }^{\text {a }}$ In both day 10 and day 17 analyses, sample sizes for models where social female biometrics were included, were reduced (day 10: 75 nestlings; 16 females out of 21 nest-boxes; day 17: 66 nestlings, 17 females out of 22 nest-boxes). Original sample sizes where restored after reinsertion of the variable other than social female biometrics in the model

\begin{tabular}{|c|c|c|c|}
\hline & Coefficient (SE) & Wald $\left(\chi^{2}\right)$ & $P$ \\
\hline \multicolumn{4}{|l|}{ Day 10} \\
\hline Nestling sex & $0.278(0.221)$ & 1.586 & 0.201 \\
\hline Hatch date & $0.060(0.123)$ & 0.236 & 0.627 \\
\hline Brood size & $-0.365(0.265)$ & 1.899 & 0.168 \\
\hline Nestling age & $-0.037(0.232)$ & 0.025 & 0.874 \\
\hline Relative nestling mass & $1.041(0.137)$ & 57.623 & $<\mathbf{0 . 0 0 1}$ \\
\hline Social female mass ${ }^{\mathrm{a}}$ & $0.025(0.045)$ & 0.396 & 0.529 \\
\hline Social female tarsus ${ }^{a}$ & $0.103(0.237)$ & 0.188 & 0.665 \\
\hline D. gallinae density (day 23 ) & $-0.111(0.081)$ & 0.706 & 0.401 \\
\hline A. casalis density (day 23 ) & $0.003(0.103)$ & 0.001 & 0.975 \\
\hline \multicolumn{4}{|l|}{ Day 17} \\
\hline Nestling sex & $0.039(0.162)$ & 0.059 & 0.808 \\
\hline Hatch date & $0.125(0.052)$ & 5.635 & 0.018 \\
\hline Brood size & $-0.026(0.109)$ & 0.058 & 0.810 \\
\hline Nestling age & $0.078(0.110)$ & 0.455 & 0.500 \\
\hline Relative nestling mass & $0.276(0.073)$ & 14.454 & $<\mathbf{0 . 0 0 1}$ \\
\hline Social female mass ${ }^{\mathrm{a}}$ & $0.019(0.013)$ & 2.385 & 0.123 \\
\hline Social female tarsus ${ }^{\mathrm{a}}$ & $0.005(0.012)$ & 0.187 & 0.665 \\
\hline D. gallinae density (day 23 ) & $0.0390(0.062)$ & 0.398 & 0.528 \\
\hline A. casalis density (day 23) & $-0.012(0.045)$ & 0.067 & 0.796 \\
\hline
\end{tabular}

that investigated an association between haematophagous parasitic mite density and body mass at day 17 , also on European Starlings, showed a negative relationship between O. sylviarum densities and body mass (Fauth et al. 1991).

To conclude, our study indicated that the trophic structure of arthropod communities nest material may play an important role in explaining nidicolous parasite-host interactions and subsequent effects on nestling condition. We have shown that it was not DG densities but AC densities that were associated with nestling mass. These relationships with the trophic role of nidicolous arthropods should not be ignored in future studies on nestling performance. There is a clear need to unravel their causality, for instance by experiments in which parasitic mite densities and predatory mite densities are manipulated to monitor their combined effect on nestling development.

Acknowledgments We acknowledge financial support from the Dutch Ministry of Agriculture, Nature and Food Quality (LNV, Expertise Center, Bennekom, The Netherlands) and the Product Boards for Livestock, Meat and Eggs (PVE, Zoetermeer, The Netherlands). Jildou van der Woude, Oscar Vedder and Hannah Dugdale provided valuable comments on earlier versions of the manuscript. Also, the comments of the anonymous referees were much appreciated. Permission for all procedures involved in the experiment was granted by the Animal Experiments Committee (DEC) of the University of Groningen (application number 5647).

Open Access This article is distributed under the terms of the Creative Commons Attribution License which permits any use, distribution, and reproduction in any medium, provided the original author(s) and the source are credited. 


\section{References}

Ardia DR (2007) Site- and sex-level differences in adult feeding behavior and its consequences to offspring quality in tree swallows (Tachycineta bicolor) following brood-size manipulation. Can J Zool 85:847-854

Axtell RC, Arends JJ (1990) Ecology and management on arthropod pests of poultry. Annu Rev Entomol 35:101-126

Badyaev AV, Hamstra TL, Oh KO, Seaman AA (2006) Sex-biased maternal effects reduce ectoparasite-induced mortality in a passerine bird. Proc Natl Acad Sci USA 103:14406-14411

Barker PS (1968) Bionomics of Androlaelaps casalis (Berlese) (Acarina: Laelapidae), a predator of mite pests of stored cereals. Can J Zool 46:1099-1102

Bauchau V (1997) Do parasitic mites decrease growth of nestling pied flycatchers Ficedula hypoleuca? Ardea 85:243-247

Bernardo J (1996) Maternal effects in animal ecology. Am Zool 36: $83-105$

Brouwer L, Komdeur J (2004) Green nesting material has a function in mate attraction in the European starling. Anim Behav 6: 539-548

Brown WP, Eggermont P, LaRiccia V, Roth RR (2007) Are parametric models suitable for estimating avian growth rates? J Avian Biol 38:495-506

Carleton RE (2008) Ectoparasites affect hemoglobin and percentages of immature erythrocytes but not hematocrit in nestling eastern bluebirds. Wilson J Ornithol 120:565-568

Chauve C (1998) The poultry red mite Dermanyssus gallinae (De Geer, 1778): current situation and future prospects for control. Vet Parasitol 79:245

Christe P, Richner H, Oppliger A (1996) Begging, food provisioning, and nestling competition in great tit broods infested with ectoparasites. Behav Ecol 7:127-131

Clark L, Mason JR (1985) Use of nesting material as insecticidal and anti-pathogenic agents by the European starling. Oecologia 67: 169-176

Clark L, Mason JR (1988) Effect of biologically active plants used as nest material and the derived benefit to starling nestlings. Oecologia 77:174-180

Clayton DH, Tompkins DM (1995) Comparative effects of mites and lice on the reproductive success of rock doves (Columbia livia). Parasitology 110:195-206

Eggert LM, Jodice PGR (2008) Growth of brown pelican nestlings exposed to sublethal levels of soft tick infestation. Condor 110:134-142

Fauth PT, Krementz DG, Hines JE (1991) Ectoparasitism and the role of the green nesting material in the European starling. Oecologia $88: 22-29$

Green AJ (2001) Mass/length residuals: measures of body condition or generators of spurious results? Ecology 82:1473-1483

Griffiths R, Double MC, Orr K, Dawson RJG (1998) A DNA test to sex most birds. Mol Ecol 7:1071-1075

Gwinner H, Berger S (2005) European Starling: nestling condition, parasites and green nest material during the breeding season. J Ornithol 146:365-371

Gwinner H, Oltrogge M, Trost L, Nienaber U (2000) Green plants in starling nests: effects on nestlings. Anim Behav 59:301-309

Johnson LS, Albrecht DJ (1993) Effects of hematophagous ectoparasites on nestling house wrens, Troglodytes aedon-who pays the cost of parasitism? Oikos 66:255-262

Kirkwood AC (1967) Anemia in poultry infested with red mite Dermanyssus gallinae. Vet Rec 80:514-515

Krist M (2009) Short- and long-term effects of egg size and feeding frequency on offspring quality in the collared flycatcher (Ficedula albicollis). J Anim Ecol 78:907-918
Lemel J (1989) Body-mass dependent fledging order in great tit. Auk 106:490-492

Lesna IK, Wolfs P, Faraji F, Roy L, Komdeur J, Sabelis MW (2009) Candidate predators for biological control of the poultry red mite Dermanyssus gallinae. Exp Appl Acarol 48:63-80

Lesna IK, Sabelis MW, van Niekerk ThGCM, Komdeur J (2012) Biological control of the poultry red mite Dermanyssus gallinae: small-scale tests in laying hen cages with predatory mites. Exp Appl Acarol (in press)

Men YT (1959) Concerning the feeding of the mite Haemolaelaps casalis (Gamasoidea, parasitiformes). Medsk Parazitol 28: 603-609 (in Russian)

Merilä J, Kruuk LEB, Sheldon BC (2001) Natural selection on the genetical component of variance in body condition in a wild bird population. J Evol Biol 14:918-929

Merino S, Potti J (1995) Mites and blowflies decrease growth and survival in nestling pied flycatchers. Oikos 73:95-103

Nilsson J-A (2003) Ectoparasitism in marsh tits: costs and functional explanations. Behav Ecol 14:175-181

Pacejka AJ, Gratton CM, Thompson CF (1998) Do potentially virulent mites affect house wrens (Troglodytes aedon) reproductive success? Ecology 79:1797-1806

Proctor H, Owens I (2000) Mites and birds: diversity, parasitism and coevolution. Trends Ecol Evol 15:358-364

Pung OJ, Carlile LD, Whitlock J, Vives SP, Durden LA, Spadgenske E (2000) Survey and host fitness effects of red-cockaded woodpecker blood parasites and nest cavity arthropods. J Parasitol 86:506-510

Rabash J, Browne W, Healy M, Cameron B, Charlton C (2008) MLwiN v2.10 beta 5. Centre of Multilevel Modelling, University of Bristol, UK

Radovsky FJ (1985) Evolution in mammalian mesostigmate mites. In: Kim KC (ed) Coevolution of parasitic arthropods and mammals. Wiley, New York, pp 441-504

Radovsky FJ (1994) The evolution of parasitism and the distribution of some dermanyssoid mites (Mesostigmata) on vertebrate hosts. In: Houck MA (ed) Mites: ecological and evolutionary analyses of life history patterns. Chapman and Hall, New York, pp $186-217$

Sabelis MW, Lesna IK, Faraji F, Komdeur J, Wolfs P, van Niekerk ThCGM (2010) Het 'Bloedluis' probleem: oplossing met roofmijten dichtbij, maar nog niet klaar voor de praktijk! Pluimveehouderij 40:22-23

Sillanpää S, Salminen JP, Eeva T (2009) Breeding success and lutein availability in great tit (Parus major) Acta Oecol 35:805-810

Szabó K, Szalmás A, Liker A, Barta Z (2002) Effect of haematophagous mites on nestling house sparrows (Passes domesticus). Acta Parasitol 47:318-322

Thomas K, Shutler D (2001) Ectoparasites, nestling growth, parental feeding rates, and begging intensity of tree swallows. Can J Zool 79:346-353

Tomas G, Merino S, Moreno J, Morales J (2007) Consequence of nest reuse for parasite burden and female health and condition in blue tits, Cyanistes caeruleus. Anim Behav 73:805-814

Verboven N, Visser ME (1998) Seasonal variation in local recruitment of great tits: the importance of being early. Oikos 81: $511-524$

Weddle CB (2000) Effects of ectoparasites on nestling body mass in the house sparrow. Condor 102:684-687

Wilkin TA, King LE, Sheldon BC (2009) Habitat quality, nestling diet, and provisioning behavior in great tits Parus major. J Avian Biol 40:135-145 